\title{
The ivory tower grays
}

\author{
The aging of the professoriate has raised questions about how to support productive faculty members late in their \\ careers while integrating the vitality of youthful scientists.
}

$A$ lthough the average age of college and graduate students who occupy lecture halls and research laboratories has not changed markedly in the past several decades, the aging of the professors on the opposite side of the lectern has become increasingly apparent. The global professoriate, which expanded during the 1950s and 1960s, is approaching retirement. As a result of increased longevity, enhanced productivity and an altered social landscape, many professors are remaining professionally active well into their 60s and beyond. It is important to explore how these changes affect faculty members, universities and aspiring young scientists.

The desire of many individuals to work well beyond arbitrarily defined age limits has led to a reevaluation of society's views of retirement. In the United States, mandatory retirement laws for tenured university faculty were abandoned in 1994, thereby bringing universities in line with broader national antidiscrimination laws. Other countries, including Australia, New Zealand and certain Canadian provinces, have adopted parallel initiatives (Nature 436, 772-773, 2005). Yet universities in some European and Asian nations still have mandatory retirement policies. Though there may be important historical and cultural reasons for maintaining such policies, faculty members who reach their nation's retirement age are often faced with a choice: retire or find another position that lacks retirement limitations. In some cases, senior professors have relocated to other countries to continue their scholarly pursuits (Science 302, 1885-1886, 2003).

The arguments in favor of abolishing mandatory retirement restrictions for university faculty are compelling. First, discrimination on the basis of age is an untenable position. Second, from a more practical perspective, many professors are productive educators and researchers well beyond traditional retirement ages. These senior scientists bring experiences and knowledge that can make them inspiring teachers and mentors for students and postdoctoral researchers. Established faculty members understand academic institutions and disciplinary cultures and thus may serve as invaluable resources to colleagues, particularly junior faculty. Finally, given their expansive knowledge built through years of learning and research, many senior professors are uniquely positioned to make continued advances at the frontiers of science.

Changes in retirement policies have already altered academic environments. A recent article (M. Bombardieri, The Boston Globe 27 December $2006, A 1)$ reported that the average age of tenured faculty members has increased in the last decade, particularly at elite institutions in the United States. For example, in 1992, the Harvard Faculty of Arts and Sciences had no tenured faculty above the age of 70 . In contrast, nearly $10 \%$ of today's Harvard professors have reached this age. In American research universities at large, the percentage of faculty age 65 or over increased from $2 \%$ to almost 6\% between 1973 and 2003 (US National Science Foundation, Science and Engineering Indicators 2006, http://www.nsf. gov/statistics/seind06/). During that same time period, the percentage of faculty over 55 increased from $15 \%$ to $30 \%$. At Harvard, faculty over 60 now outnumber those under 50 .

At the same time, there has been a dramatic increase in the age at which young investigators receive their first independent funding. In the United States in 2004, the average age for scientists receiving their first National Institutes of Health R01 grant was 42, which is five years later than their 1980 cohort. This change has been attributed to an increase in the average age at which scientists start their first independent faculty position (http://www.nih.gov/about/director/newsletter/Fall2006.htm), a statistic that may be linked to the general increase in the average age of university faculty members. In the United States, from 1973 to 2003, the percentage of faculty age 35 or under declined from $25 \%$ to less than $10 \%$ (Science and Engineering Indicators 2006). This trend creates further challenges for junior professors by delaying the start of their independent careers after an already significant time investment during graduate and postdoctoral education. As a secondary effect, a later move into the professoriate can present quality-of-life issues in areas such as family rearing and retirement savings.

Creating a system that supports senior faculty while sustaining the pipeline of young scientists remains a significant challenge to university leaders worldwide. Universities must begin to address the issue of the aging professoriate and encourage a greater balance in the distribution of faculty age, background and expertise. University administrators should first generate flexible options, rather than adopting rigid rules, that will be applied as faculty move through their careers. At retirement, for example, certain faculty may prefer a complete departure from the university. Others may wish to remain connected, but perhaps in a more administrative or educational role. Yet another group may seek to continue their research as active emeritus faculty members. Universities must be accommodating to these different goals. Simultaneously, universities need to pay particular attention to the recruitment and retention of future faculty members. Because assistant professors are currently more likely to be women, underrepresented minorities, and scientists working in new interdisciplinary fields, such as chemical biology, the coming decades offer an unparalleled opportunity to achieve greater diversity in academia.

Although forward-looking universities have been planning for the effects of an aging professoriate for many years, recent trends suggest that the issue deserves much greater attention among today's faculty and university leaders. These decision makers must provide answers to the major questions facing academia's future, including: what retirement options are appropriate and reasonable for research universities? What are the appropriate space and funding levels for scientists at different career stages? How does the changing face of the professoriate affect the current tenure system? Though the challenges and answers will likely be different for each country, there is a global need to reevaluate how we sustain and nurture academic faculty — one of science's greatest resources. 